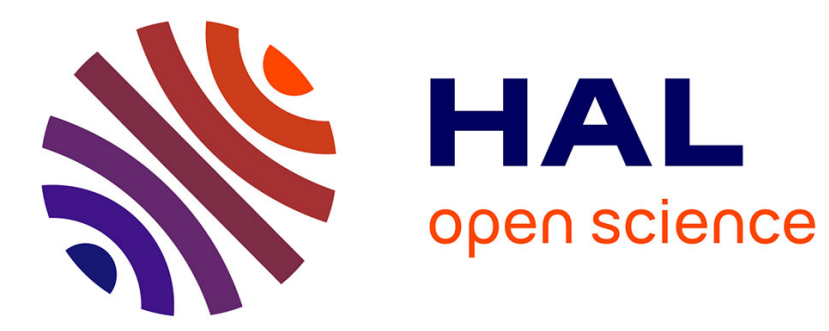

\title{
Key performance indicators in Tour de France sailing
} Kilian Philippe, Thierry Paillard, Romain Dubois, Olivier Maurelli, Jacques

Prioux

\section{To cite this version:}

Kilian Philippe, Thierry Paillard, Romain Dubois, Olivier Maurelli, Jacques Prioux. Key performance indicators in Tour de France sailing. Journal of Sports Sciences, 2021, 39, pp.944-954. 10.1080/02640414.2020.1851925 . hal-03038623

\section{HAL Id: hal-03038623 https://hal.science/hal-03038623}

Submitted on 23 Feb 2021

HAL is a multi-disciplinary open access archive for the deposit and dissemination of scientific research documents, whether they are published or not. The documents may come from teaching and research institutions in France or abroad, or from public or private research centers.
L'archive ouverte pluridisciplinaire HAL, est destinée au dépôt et à la diffusion de documents scientifiques de niveau recherche, publiés ou non, émanant des établissements d'enseignement et de recherche français ou étrangers, des laboratoires publics ou privés. 


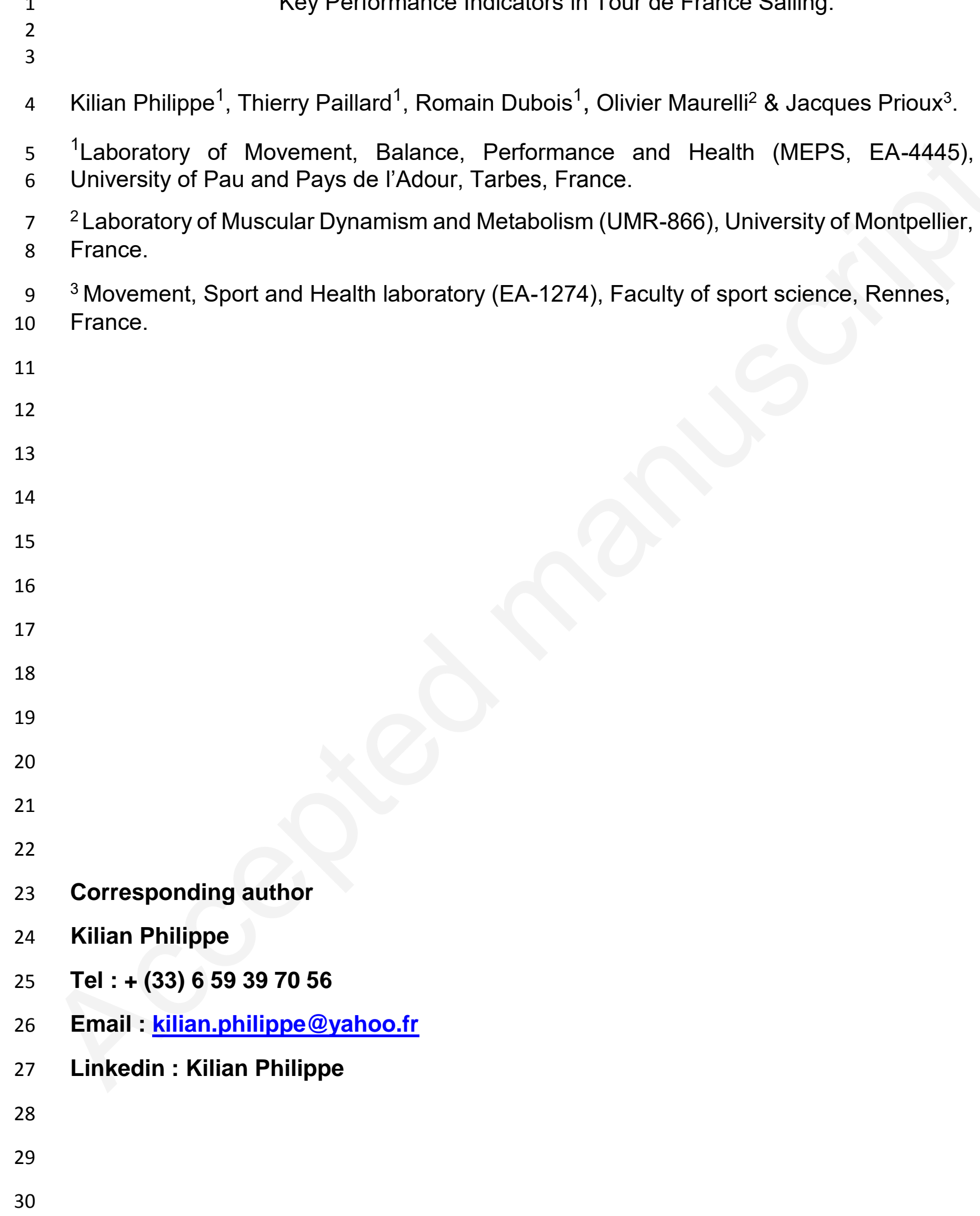

$4 \quad$ Kilian Philippe ${ }^{1}$, Thierry Paillard ${ }^{1}$, Romain Dubois ${ }^{1}$, Olivier Maurelli ${ }^{2} \&$ Jacques Prioux ${ }^{3}$.

5 'Laboratory of Movement, Balance, Performance and Health (MEPS, EA-4445), 6 University of Pau and Pays de l'Adour, Tarbes, France.

72 Laboratory of Muscular Dynamism and Metabolism (UMR-866), University of Montpellier, 8 France.

$9{ }^{3}$ Movement, Sport and Health laboratory (EA-1274), Faculty of sport science, Rennes, 10 France.

23 Corresponding author

24 Kilian Philippe

$25 \quad$ Tel : + (33) 659397056

26 Email : kilian.philippe@yahoo.fr

27 Linkedin : Kilian Philippe

1

2

3 
Abstract

32 This study aimed to determine the key performance indicators of inshore sailing during 33 the sailing Tour de France. Technical and physical parameters were investigated to 34 determine the discriminating factors between successful and less successful international 35 level sailors. Measurements from 21 sailors (mean \pm SD; age $=23.81 \pm 4.18$ years) were 36 conducted prior to the sailing Tour de France. Global Positioning System data of all 37 participating teams $(n=23)$ was analyzed. Sailors were divided in two groups (i.e. 38 successful and less successful) according to qualifying performance percentage. The 39 differences between successful and less successful sailors were explored by means of 40 independent t-tests. Results indicate that successful boats displayed higher maximal 41 speed, higher average speed and more efficient starting performance per race than less 42 successful boats. Successful sailors have stronger handgrip strength, higher isometric 43 maximal voluntary force relative to bodyweight (isometric mid-thigh pull) and more 44 powerful submaximal pulling (bench pull) actions than their less successful counterparts. 45 The results of this study suggest that multiple sailing, physical and physiological variables 46 are related to sailing performance in inshore sailing. Therefore, we emphasize the 47 importance of integrating specific testing protocols to evaluate the performance potential 48 of inshore sailors participating in the sailing Tour de France.

50 Keywords: Sailing, Tour de France, Elite Athletes, Inshore sailing. 51 


\section{Introduction}

61 This study focuses on inshore sailing performance in multihull-crewed vessels. The sailing 62 tour de France (TDF) is one of Europe's major annual inshore sailing event. For over 40 63 years, this competition has allowed some of the world's best sailors to compete along the 64 French coastline. Today, the competition sees teams engage in regattas aboard the 65 Diam24 One Design (D24) trimaran.

66 The D24 vessel is $7.5 \mathrm{~m}$ long, $5.62 \mathrm{~m}$ wide, has a mast height of $11.5 \mathrm{~m}$, a total sail area 67 of $70 \mathrm{~m}^{2}$ and is primarily made of composite material. It is maneuvered by three highly 68 skilled sailors; helmsman, trimmer and bowman (Figure 1). During the TDF, the boat 69 competes in different stages; the "nautical stadium" (NS; n=10) and "coastal raid" (CR; $70 \mathrm{n}=5)$ events. A NS is a short but intense stage that consists of qualification heats (2-6 per 71 NS day). Teams race to tally points in the aim to qualify for the daily final (Figure 2). The 72 boats are sailed in a fleet-race format (i.e. two groups of 11-12 teams) around a 1-3 lap 73 (according to committee) beam reach, downwind and upwind course of $2672.9 \pm 610.3$ $74 \mathrm{~m}$. The best four teams of each fleet are selected to advance to the daily final. A CR is an 75 event that tests the sailor's ability to race on larger and longer courses (59100 \pm 19400 $76 \mathrm{~m}$ ) upon the coastline.

77 Although the TDF has established its' importance in the sailing environment, performance 78 studies are still scarce in sports literature. This is partly due to two distinguishing external 79 parameters that make such analysis unsteady. First, the TDF is unique in that the format 80 changes annually according to host cities participating to the edition. The influence of 81 geographical location has a significant impact on uncontrollable parameters such as 82 weather and sea conditions. Second, the ever-evolving development of technology and 83 hydrodynamic research leads to constant changes of the official TDF vessel. This 84 ultimately influences the conditions specific to the race. Nevertheless, despite the singular 85 nature of the TDF, it would be interesting to collect data relative to sailing events (i.e., race 86 task analysis) and qualities required (i.e., key performance indicators) in order to better prepare athletes for this sport competition.

88 Sport performance requires the optimal exploitation of the athletes' potential, but little is 89 known about the contribution of different factors (i.e. physiological, psychological, 90 technical and tactical/strategic) in sailing performance. To date, it was mainly reported 
91 that sailing is a sport for which bio-informational and strategic qualities are fundamental 92 (Araújo et al., 2015). Although the anthropometric, physical and physiological 93 characteristics are essential to performance in most sports, their influence on sailing 94 performance still remains to be analyzed. Establishing normative data, by engaging in 95 profiling approaches, would be a valuable mean to understanding the needs for optimizing 96 sport specific performance. Such data would be promoting a better understanding for

\section{Materials and methods}

\section{Subjects}

Professional male international inshore sailors $(N=21$; mean $\pm S D$; age $=23.81 \pm 4.18$ years; height $=179.32 \pm 7.30 \mathrm{~cm}$; body mass $=74.78 \pm 6.56 \mathrm{~kg}$ ) were assessed in the final preparation phase leading up to the 2019 TDF. Subjects were informed of the testing procedures, potential risks and the purpose of their participation. All subjects had already competed in international competitions. Their collective experience included 59 TDF campaigns. At the time of testing, the subjects had completed 6 months of sailing training and had been actively participating in strength and conditioning programs for at least three years. None of the participants reported injuries or diseases that would impair their physical performance. The study protocol was approved by the ethics committee of Rennes University. Written informed consent was obtained from all participants before the start of the study. In this study, criteria used to qualify an athlete's performance was based on the team's final ranking. An athlete was categorized as "successful" (SA, $n=10)$ if he 
crewed a successful boat $(\mathrm{SB})$. Less successful athletes $(\mathrm{LSA}, \mathrm{n}=11)$ crewed a less successful boat (LSB).

\section{Procedures}

Subjects were signed up for 2 testing sessions: a) anthropometry and b) physical and physiological. Both $a$ ) and b) testing sessions were completed on the same day. Subjects were instructed to rest adequately 72 hours before testing and to maintain normal eating and drinking habits during this period. The first session consisted of anthropometric measurements. These measurements took place in the morning upon waking up. Athletes were asked to refrain from eating two hours prior to testing and to avoid caffeine consumption twelve hours before. The second session was directed towards evaluating the physical and physiological components. The testing took place two hours post breakfast. The subjects were asked to not change their nutritional habits during this meal. Before all testing, a standardized warm-up was completed including jogging, dynamic movements, and stretches. Each physical and physiological quality measured was fully explained and demonstrated before testing.

\section{Regatta analysis}

137 The $42^{\text {nd }}$ sailing Tour de France took place in July 2019 and was held in 7 French coastal 138 cities. This edition was disputed between 23 international teams over 17 days (10 NS and $1395 \mathrm{CR}$ ) interspersed by two days of recovery. This resulted in 99 races (84 qualifying heats, 14010 finals and $5 \mathrm{CR}$ ). Points were attributed daily according to results (i.e.: $1^{\text {st }}$ receives 50 points, $2^{\text {nd }}$ receives $49 \ldots$ last receives 28 ) and were accumulated throughout the competition. The final ranking established the winner of the TDF.

143 Race data - including sailing distance $(\mathrm{m})$, average speed $\left(\mathrm{m} . \mathrm{s}^{-1}\right)$, maximal speed $(\mathrm{m} . \mathrm{s}-$ ${ }^{1}$ ), course coverage (\%) (i.e., distance sailed / course distance), start performance (rank and time gap at the first mark) and maneuvers (tack and gybe; count) - were collected during all 84 qualifying heats and 5CR. GPS units (Mylaps ${ }^{\circledR}$ X5 Global Positioning System; 9-channel GPS receiver; location measurement accuracy 2.5 m; dimensions 109 $\times 59 \times 22 \mathrm{~mm}$; weight $95 \mathrm{~g}$; temperature range $-20-+55^{\circ} \mathrm{C}$ ) were placed on all of the 23 boats. A boat was categorized as "successful" $(\mathrm{SB}, \mathrm{n}=7)$ if it qualified for more than half 
of the daily finals. Less successful boats (LSB, $n=16$ ) qualified for half or less of the daily finals.

\section{Anthropometric, physical and physiological assessment}

\section{Session 1: Anthropometric measurement.}

Anthropometric characteristics were measured in the following order: weight, height, sitting height, wingspan, skinfolds and body girths. A weighing scale (Seca ${ }^{\circledR}$, Hamburg, Germany) and a stadiometer (Seca ${ }^{\circledR}$, Barcelona, Spain) were used to measure weight and height respectively. Measurements for height (standing and sitting) and weight were made with an accuracy of $0.5 \mathrm{~cm}$ and $0.1 \mathrm{~kg}$ respectively. Wingspan was measured to the nearest $0.1 \mathrm{~cm}$, from one middle fingertip to the other using a measuring tape (Seca®, Barcelona, Spain). Three skinfolds were taken on the right side of each participant (pectoral, abdominal and thigh) according to recommendations by Jackson and Pollock (Jackson and Pollock, 1978). The skinfolds were measured with a Harpenden skinfold caliper (Harpenden®, Burgess Hill, UK) with $10-$ g. $\mathrm{mm}^{-2}$ of constant pressure. Body density was assessed (Jackson and Pollock, 1978) while body fat was calculated using Brozek's equation (Brozek et al., 1963). A measuring tape (Seca®, Barcelona, Spain) was used to measure the girth of relaxed arms, thighs and calves on left and right sides following measuring recommendations of the international society for the advancement of kinanthropometry (ISAK; Marfell-Jones et al., 2006).

Session 2: Physical testing.

Physical and physiological characteristics were measured in randomized order.

Handgrip strength. Maximal isometric hand-grip strength (HGS) was assessed with a Jamar® handgrip dynamometer (Sammons Preston Corp., Bolingbrook, III., USA). The test positions were standardized (Svantesson et al., 2009). Three trials were performed on each hand. The first three trials started with the right hand. Subjects were instructed to squeeze the device as hard as possible for $3 \mathrm{~s}$. The time between each trial was $15 \mathrm{~s}$ and 3 min of rest was allowed when changing hands. The maximal measure of the three trials 


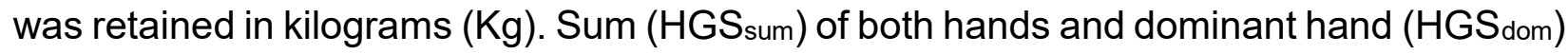
measures were assessed and included in the results.

Vertical jumps. Lower body power was tested on the squat jump (SJ) and countermovement jump (CMJ) using a chronojump contact mat (ChronojumpBoscosystem $^{\mathrm{TM}}$, Software, Spain). Each subject had three attempts per jump with 1 min of rest between trials. Subjects started with SJ and, after a 3 min passive recovery, were assessed on CMJ. Instructions for the jumps were explained and controlled with a goniometer for the SJ. Subjects were instructed to descend to $90^{\circ}$ knee flexion. Once position was reached, a countdown of " $3,2,1$, jump" was indicated orally. A validated and reliable smartphone application (Balsalobre-Fernandez et al., 2015) was used for lateral video analysis. This allowed to track lateral kinematics and thus avoid collecting results that involved a countermovement action. Both the SJ and CMJ were done with subjects placing hands on their hips as to avoid arm movement. For the CMJ, athletes were instructed to perform a rapid eccentric phase, immediately followed by a rapid concentric phase with the intention to jump as high as possible. Height and peak power of the best $\mathrm{SJ}\left(\mathrm{SJ}_{\mathrm{H}}\right.$ and $\left.\mathrm{SJPP}\right)$ and $\mathrm{CMJ}\left(\mathrm{CMJ}_{\mathrm{H}}\right.$ and $\left.\mathrm{CMJPP}\right)$ performances were reported for analysis.

Isometric mid-thigh pull. Testing for isometric mid-thigh pull (IMTP) was conducted on a customized pulling rack apparatus specifically developed for data collection. IMTP was performed using two portable force platforms sampling at $1000 \mathrm{~Hz}\left(\mathrm{Pasco}^{\mathrm{TM}}\right.$, Rosedale, USA) and previously validated (Peterson Silveira et al., 2017). The force plates were connected to a portable laptop running the Capstone Software Program (Pasco ${ }^{\mathrm{TM}}$, Rosedale, USA). Knee angle was measured with a goniometer, to ensure a range of 125$140^{\circ}$ (Haff et al., 2013). The bar height was adjusted to meet the testing criteria and to accommodate to the athlete's size. Once the test had been thoroughly described and testing parameters were set, a specific warm-up was conducted. Athletes were provided with two warm-up pulls, 1 at $50 \%$ and 1 at $75 \%$ of perceived maximum effort, separated by $1 \mathrm{~min}$ of rest. Once body position was stabilized (verified by observation and live force measures), the subject was given a countdown of " $3,2,1$, pull." Minimal pre-tension was allowed to ensure that there was no slack in the subject's body before initiation of the pull. Athletes performed 3 maximal IMTP with the instruction to pull the bar with maximal effort 
as quickly as possible and push the feet down into the force platform. The time between each trial was $1 \mathrm{~min}$. Each maximal isometric trial was performed for $5 \mathrm{~s}$. The best trial was used for data collection and was analyzed relatively to the athlete's body weight (IMTPw).

212 Force-velocity pulling profile. Force-velocity curve testing on the bench-pull (BP) was conducted on an elevated bench-pull device placed above a guided squat rack (Smith machine). The Smith machine (Technogym ${ }^{\circledR}$, Cesena, Italy) allowed for vertical displacement through guided rods. A Chronojump linear position transducer (Chronojump ${ }^{\mathrm{TM}}$, Barcelona, Spain) was placed below the bar and automatically calculated the kinematic parameters of every repetition. Subjects were instructed to pull the bar with maximum effort until the barbell hit the bench $8 \mathrm{~cm}$ below the subject's chest. The barbell was then lowered and a brief pause of $1 \mathrm{~s}$ was observed to avoid the rebound effect or any stretch-shortening cycle interference. The protocol followed Sanchez-Medina's instructions (Sanchez-Medina et al., 2014). Initial load started at $20 \mathrm{~kg}$ and increased by increments of $10 \mathrm{~kg}$ until mean propulsive velocity (BPMPV) was lower than $0.7 \mathrm{~m} . \mathrm{s}^{-1}$. Three attempts were executed for light (<50\% 1RM), 2 for medium (50-80 \% 1RM) and only 1 for the heaviest (> $80 \%$ 1RM) loads. Inter-set rest intervals were 3 min for the light and medium loads and $5 \mathrm{~min}$ for the heaviest loads. The fastest bar speed for each load was recorded. The maximum load that could be lifted once was considered the athlete's 1RM $\left(\mathrm{BP}_{1 \mathrm{RM}}\right.$ ). BPMPV was calculated for the loads that were completed by all subjects (BPMPV20, $\mathrm{BP}_{\mathrm{MPV} 30,} \mathrm{BP}_{\mathrm{MPV} 40}$ and $\mathrm{BP}_{\mathrm{MPV} 50)}$.

Anaerobic capacity. Anaerobic capacity was tested using a modified rowing Wingate test (MRWT) on a rowing ergometer Concept II-D (Concept 2 INC ${ }^{\text {TM }}$, Vermont, USA). The flywheel was set at 130 drag factor. Subjects were allowed 3 min of warm-up at a rate of perceived exertion of 5 out of 10 . Athletes then completed the $30 \mathrm{~s}$ all-out test. Exercise performance was expressed as mean power output (MPO) in watts (W) and was calculated automatically by Concept II-D. The procedure has been described previously (Riechman et al., 2002).

236 Maximal oxygen uptake. Maximal oxygen uptake $\left(\dot{\mathrm{V}}_{2 \max }\right)$ was assessed through a step 237 incremental test (MOU ${ }^{25}$ ) on an electromagnetically braked cycle ergometer (Kettler® 
Ense-Parsit, Germany). $\dot{V} \mathrm{O}_{2 \max }$, expressed as $\mathrm{ml} \cdot \mathrm{min}^{-1} \cdot \mathrm{kg}^{-1}$, measures were collected through the use of a portable self-contained metabolic cart CardioCoach (Korr Medical Technologies $®$, Salt Lake City, UT) and previously validated (Dieli-Conwright et al, 2009). Subjects were given time to adjust seat and bar height before starting the test. MOUT25 started at $20 \mathrm{~W}$ and increased by $25 \mathrm{~W} \cdot \mathrm{min}^{-1}$ until voluntary exhaustion (Amann et al., 2004). A cadence of 90-100 RPM was standardized throughout the test. During the MOUT25 the following variables were constantly registered: heart rate (HR), minute ventilation $\left(\dot{\mathrm{V}}_{\mathrm{E}}\right)$ and oxygen uptake $\left(\dot{\mathrm{V}}_{2}\right)$. Prior to each test, the gas analyzer was calibrated according to the manufacturer's specifications. $\dot{\mathrm{V}}_{2 \max }$ was determined when physical signs suggestive of exhaustion were apparent and at least one of the following two criteria were met; (1) HR max was no less than 15 beats below the predicted maximum [220 - (0.65 x age); Spiro 1977] and (2) a steady state of $\dot{\mathrm{VO}}_{2}$ despite an increase in workload (Vehrs et al., 2007).

\section{Statistics}

252 Data was calculated through standard statistical methods and are presented as mean \pm 253 standard deviation. All variables were considered normally distributed through analysis with the Shapiro-Wilk test, histograms and skewness values prior to analysis. One-way analysis of variance (ANOVA) was used to compare anthropometric, physiological and physical measures for the different crew positions. Independent t-tests were performed to determine if significant differences existed between physical profiles (SA vs. LSA) and technical parameters (SB vs. LSB). When results were significantly different, an effect size (ES) calculation was used. ES was evaluated using Cohen's $d$ along with $95 \%$ confidence intervals. ES of $\leq 0.2,0.21-0.60,0.61-1.20,1.21-2.0, \geq 2.0$ were considered as trivial, small, moderate, large and very large, respectively (Batterham and Hopkins 2006). Finally, Spearman's Rank Order Correlation ( $r$ ) was used to identify the relationship between outcome (race and overall standings) and the key performance indicators identified as significant in the independent t-tests. Statistical analyses were performed using the SPSS package (15.0 version; SPSS, Inc., Chicago, IL, USA). The level of significance was set at $p<0.05$.

\section{Results}


Regatta analysis

Mean race duration was $17 \pm 2$ min for NS and $244 \pm 35$ min for CR. Course distance was $2672.9 \pm 610.3 \mathrm{~m}$ for NS and $59000 \pm 17500 \mathrm{~m}$ for CR. Teams participated between 47 and 57 races and accumulated $474.3 \pm 38.3$ maneuvers (NS: $355.1 \pm 37.8$; CR: $119.1 \pm$ 6.6). Gybes (downwind maneuver; lasted $\sim 12 \mathrm{~s}$ ) were more recurrent than tacks (upwind maneuver; lasted $\sim 8 \mathrm{~s}$ ), respectively $259.3 \pm 26.8$ vs. $214.9 \pm 26.1$. Maneuver count per NS heat was $8.7 \pm 0.9$ and $23.8 \pm 1.3$ for CR. Sailing distance for NS heats was $4161.8 \pm$ $80.1 \mathrm{~m}$ and $78500 \pm 34900 \mathrm{~m}$ for CR. Course coverage for NS was $158.5 \pm 3.0 \%$ and $133.8 \pm 4.9 \%$ for $\mathrm{CR}$.

\section{Technical key performance indicators}

Sailing parameters collected during the TDF are analyzed in Table 1 for SB, LSB and all boats. Race outcome for NS was significantly correlated $(p<0.01)$ with starting performance $(r=.52)$, maximal speed $(r=.33)$ and average speed $(r=.76)$. Coastal raid ranking was correlated $(p<0.01)$ with starting performance $(r=.58)$, maximal speed $(r=.43)$ and average speed $(r=0.81)$. All three of the highlighted performance parameters were also significantly correlated to final rankings of the TDF.

\section{Profiling and physical key performance indicators}

Table 2 shows mean $( \pm S D$ ) for the age and anthropometric characteristics of professional male TDF sailors. No significant differences were observed in anthropometric parameters between crew positions (Table 2) and success attribute. The physical and physiological profiles of sailors are reported in Table 3. Successful sailors had stronger HGS Dom $_{\text {m }}$ $(E S=0.82)$ and IMTPw relatively to body weight $(E S=0.93)$ and exerted faster $B P_{M P V 20}$ $(E S=1.18)$ than their less successful counterparts. The differences between SA and LSA were significant $(p=0.001)$. HGS $_{\text {Dom }}(r=0.54), \operatorname{IMTPw}(r=0.41)$ and BPMPV20 $(r=0.61)$ were significantly correlated $(p<0.01)$ to rank in NS heats. CR results were correlated to $\mathrm{HGS}_{\text {Dom }}$ $(r=0.37 ; p<0.05)$ and $\mathrm{BP}_{\mathrm{MPV} 20}(r=0.74 ; p<0.01)$. BPMPV20 showed strong correlation with final TDF rankings $(r=0.8 ; p<0.05)$.

\section{Discussion}


The aim of this present study was threefold. First, our objective was to analyze and report the nature of sailing during the TDF. Second, we attempted to identify the key performance indicators associated with racing outcome. Third, we directed a descriptive analysis of anthropometric, physical and physiological profiles of elite level sailors participating in the TDF. Most prominently, the analysis has indicated the capacity to discriminate between SB/LSB and SA/LSA by considering technical and physical parameters.

\section{Regatta analysis}

This is the first report on the nature of sailing during the TDF. Overall, sailors travelled $541300 \pm 64900 \mathrm{~m}$ in $1792.3 \pm 409.3 \mathrm{~min}$ during the 15 days of competition. Mean race duration (SN: $17 \mathrm{~min}$; CR: $244 \mathrm{~min}$ ) and the number of maneuvers were highly variable due to external parameters (e.g. race course and tactics, environmental condition). Insights on the nature of energetic demands and work to rest ratio can nevertheless be estimated. In sailing, particularly where sailors must hike, work to rest ratio should be reevaluated as a dynamic to static effort ratio. Tacking maneuvers lasted around $8 \mathrm{~s}$ while a gybe lasted around $12 \mathrm{~s}$. High intensity efforts, linked to the demands of maneuvering (Neville et al., 2009), occurred on a 1:14 ratio in NS and 1:50 in CR. Dynamic to static ratio reached as high 1:10 when boats chose to sail a course close to shoreline (CR). Hence, it can be assumed that the anaerobic energy system is significantly stressed during TDF racing. However, the TDF competition also requires a good aerobic level to endure the 15 days of sailing and to optimize recovery when racing (NS: $77 \pm 14$ min.stage ${ }^{-1}$; CR: $244 \pm 35$ min.stage ${ }^{-1}$ ).

\section{Technical key performance indicators}

GPS technology permits performance analysts to monitor external training load (Cummins et al., 2013) and collect data to identify technical and tactical performance indicators in sailing activities (Perez Turpin et al. 2009). Research has identified the key technical performance indicators in windsurfing (Anastasiou et al., 2019), match racing 
(Neville et al., 2009) and kiteboarding (Caimmi and Samprini, 2017). To the best of our knowledge, this is the first study to analyse such parameters in fleet racing.

With regards to our results, we observed variability in the distance covered and time to finish a heat. Wind direction and wind speed influences the organisation committee in course settings (Perez Turpin et al., 2009). Nevertheless, it should be noted that sailing also relies on cognitive skills (Araújo et al., 2015) and that different racing strategies exist. Teams must regularly analyse weather and oceanographic reports to determine the most appropriate course (Thill, 1982). Other external parameters (e.g., position in the fleet, changes of racing conditions, placement of opponents on course) can provoke variations and modifications in initial strategy (Araujo and Sepra, 1997; Ward, Williams and Bennett, 2002; Manzanares, Segado and Menayo, 2012).

Speed parameters have previously discriminated between successful and less successful athletes in other sailing competitions (Anastasiou et al., 2019; Caimmi and Samprini, 2017). This comforts our findings in that both average speed and maximal speed were significantly correlated to both race and TDF overall outcome. On the basis of bio-informational data, one can assume that SB were more efficient in determining the most favourable course to take in order to optimize boat speed. Pluijms et al. (2015) have investigated the difference in visual fixation behaviour between top and bottom-ranked sailors. On the one hand, bottom ranked sailors focus their centre of attention on the boat and thus might discard important environmental information. On the other hand, top ranked sailors, were capable of "feeling" the changes in boat speed and direction through mechanical and proprioceptive feedback. SB also displayed better starting performance (rank and time gap at first mark) than LSB. Starting performance was significantly correlated with race outcome and overall TDF ranking. This could be due to sailors changing their gaze to look for relevant environmental information that might enhance the boat's performance (Pluijms et al., 2015). Indeed, if boats arrived first at the first mark they would not have to account for other information concerning opposing team position.

Profiling and physical key performance indicators 
Although sailing has acquired research interest through important international events (i.e. Americas Cup and Olympic Games), none has analyzed the anthropometric, physical and physiological demands for multihull fleet racing. Hence, we can only compare our data to those of similar sailing events. The mean data for height and weight of the 21 subjects (179.3 $\pm 7.3 \mathrm{~cm}$ and $74.8 \pm 6.6 \mathrm{~kg}$ ) are different to those found in other studies. Indeed, offshore sailors tended to be smaller and heavier $(177 \pm 7 \mathrm{~cm}$ and $78 \pm 10 \mathrm{~kg}$; Hurdiel et al., 2014) whilst measures reported on the 2002 TDF outlined the smaller and lighter profiles of sailors at the time $(173 \pm 6 \mathrm{~cm}$ and $62.6 \pm 9.3 \mathrm{~kg}$; Leger et al., 2008). The body fat of athletes in the study hereby $(12.91 \pm 4 \%)$ was similar to previously reported data of America's Cup sailors (13 $\pm 4 \%$; Neville et al., 2009), and seems within the range (10-15\%) of international and Olympic dinghy sailors (Vangelakoudi et al., 2007; Bojsen-Moller et al., 2007). Anthropometric characteristics vary according to competitive status, crew position, publishing date and sailing classification (Larsson et al., 1996). Surprisingly, there was no significant difference in anthropometric data in regards to crew position (Table 2). This could be the result of the race organization's choice to set the minimal total crew weight to $210 \mathrm{~kg}$ and supports findings by Neville et al., 2009 that highlights the modern sailors' strategy to reduce body fat of the whole crew as to maximize lean muscle mass for roles demanding higher physical output. This outlines the complexity when establishing normative data for sailing in general.

The physical and physiological characteristics reported in the present study also varied when compared to other sailing studies. $\dot{\mathrm{V}}_{2 \max }$ of our present study $(53.4 \pm 8.5$ $\left.\mathrm{ml} \cdot \mathrm{mn}^{-1} \cdot \mathrm{kg}^{-1}\right)$, seems to be (i) lower than in elite laser sailors $\left(58.2 \pm 4.7 \mathrm{ml} \cdot \mathrm{mn}^{-1} \cdot \mathrm{kg}^{-1}\right.$; Castagna and Brisswalter, 2006), (ii) higher than finn sailors (47.6 $\pm 3.5 \mathrm{ml} \cdot \mathrm{mn}^{-1} \cdot \mathrm{kg}^{-1}$; Bojsen-Moller et al., 2007) and (iii) similar to America's Cup grinders (52.2 $\pm 4.6 \mathrm{ml}^{\mathrm{mn}}$ ${ }^{1} . \mathrm{kg}^{-1}$; Bernardi et al., 2007). The differences outlined in these studies could be related to the effect induced by the various peculiar onboard activity and/or the use of various testing methodologies. Nevertheless, research has outlined the low aerobic demands during a dinghy regatta (Portier et al., 2003). Indeed, sailors participating on TDF engage in high intensity hoisting and trimming actions when maneuvering. Between the different maneuvers, the sailors are involved in quasi-isometric hiking. Previous studies showed a significantly decreased oxygenation pattern in the $\mathrm{m}$. Vastus Lateralis during hiking 
(inherent to isometric contractions $>30 \%$ maximal voluntary contraction), indicating an imbalance between oxygen supply and demand, and probably due to restricted muscle blood flow (Bourgois et al., 2016). The sailors undertaking the MRWT-MPO test in this study $(565.9 \pm 97.9 \mathrm{~W})$ held similar anaerobic capacity than highly trained college level rowers (548.97 $\pm 95.57 \mathrm{~W}$; Shaharudin and Zanotto, 2014). This comforts our understanding that TDF sailors rely significantly on anaerobic energy delivery during racing.

Lower body power was assessed using SJ and CMJ protocols. Few other studies have analyzed such parameters on sailors. Indeed, only one has assessed national level sailors for lower body power (Tan et al., 2006) and found similar results to the present study $(36.0 \pm 6.2$ vs $34.0 \pm 4.0 \mathrm{~cm})$ on the SJ. Nevertheless, it seems that no correlation between jumping performance and hiking potential exists (Tan et al., 2006). Hiking is characterized by strong isometric contractions and coactivation of the muscles involved: quadriceps, hamstrings, abdominal and paravertebral muscles (Larsson et al., 1996; Tan et al., 2006). Numerous studies have analyzed isokinetic muscle strength of knee, hip and trunk flexors and extensors of elite level sailors (Aagaard et al., 1998; Chicoy and Encarnacion-Martinez, 2015). These studies have highlighted the high demands of these specific strengths on hiking performance. In the present study, to assess maximal isometric strength of the lower body, an IMTP test was performed. To date, this is the first study to use such a protocol in an elite sailing environment. Relative strength should be considered when assessing sailors, or other sports, where body weight is regulated by competition rules. Isometric maximal voluntary force, using the IMTP test, has been linked to functional performance in sport (Ran-Wang et al. 2016). We aimed at analyzing isometric strength at hip/knee angles like those of other sailing studies (Chicoy and Encarnacion-Martinez, 2015) by using the IMTP. Interestingly, maximal IMTP discriminated between SA and LSA when the results were compared relatively to bodyweight (IMTPw). IMTPw performance was significantly correlated $(r=0.41 ; p<0.01)$ with rank on NS courses. These results suggest that a high level of relative strength is necessary in TDF sailors, and supports the findings in other studies analyzing the relationship between lower body strength and sailing performance (Blackburn and Hubinger, 1995). 
Trimming and hoisting actions requires powerful and energetic movements on the sheets (Bay and Larsson, 2013). By doing so, sailors increase the amount of apparent wind that covers the sail and, thus, increase boat speed. Indeed, it was thought that sailors participating in the TDF would have high amounts of maximal strength due to the predominance of pulling actions necessary when maneuvering the boat. Differences can be outlined for the one repetition maximum between Americas Cup sailors (99.41 \pm 5.4 $\mathrm{kg}$; Pearson et al., 2009) and TDF sailors of this present study $(77.5 \pm 13.0 \mathrm{~kg})$. Nevertheless, it should be noted that the America's cup sailors were heavier (97.8 \pm 12.5 vs $74.8 \pm 6.6 \mathrm{~kg}$ ). Bar velocity at fixed loads was also evaluated and turned out to be significantly different between SA and LSA at $20 \mathrm{~kg}$ loads. Neville and collaborators (2009) reported that successful boats maneuvered faster than less successful boats. Faster bar velocity at submaximal loads could be directly correlated to hoisting/trimming efficiency and, thus, sailing performance through faster maneuvers. $\mathrm{BP}_{\mathrm{mpv} 20}$ was in fact significantly correlated to racing outcome (NS and $C R)$ and TDF final ranking $(r=.80 ; p<0.05)$. Future research should therefore aim at establishing associations between bar velocities at fixed loads with hoisting actions.

Handgrip strength has received a considerable amount of interest in past research. Indeed, it has been linked to performance in many sports (Cronin et al., 2017). Significant decreases in grip strength between pre- and post-sailing training sessions have been reported in junior male semi-elite sailors (Bateup et al., 2016). The TDF sailors (61.1 \pm 9.5 $\mathrm{kg}$ ) reported stronger $\mathrm{HGS}_{\text {Dom }}$ than collegiate dinghy sailors (48.28 $\pm 5.31 \mathrm{~kg}$; Pulur, 2011). These results outline the high mechanical stress placed on forearms when maneuvering TDF boats. HGSDom was found to significantly discriminate between SA and LSA. It was also correlated to racing outcome (NS and CR). These results could indicate more efficiency to maneuver the D24 at higher speeds (i.e. optimized gripping ease against high resistance in sheets and cranks). It would seem interesting to analyze the acute and chronic load effects of sailing on handgrip strength.

An interesting finding of this study was that no significant difference was found between crew positions for physical and physiological parameters. This could indicate an equal importance of overall fitness of TDF sailors to maneuver the boat. Indeed, it was 
not rare to see sailors switch position when racing or during specific maneuvers throughout the TDF. Comparison of physical and physiological parameters from 21 elite sailors indicated that SA had greater strength (HGS Dom), muscular voluntary contraction (IMTPw) and power (BP $\left.\mathrm{Bpv}_{20}\right)$ compared to LSA. Differences were most marked between trimmers (IMTPw, BPmpv20, $\mathrm{BP}_{\mathrm{mpv} 30}$ and $\left.\mathrm{BP} \mathrm{mpv}_{40}\right)$ and bowmen $\left(\mathrm{BP}_{\mathrm{mpv}} 20\right)$ which are primarily responsible for trimming and material handling (sails, ropes and cranks). A possible explanation highlighting the difference in HGS Dom found in this study could result from higher training loads on-water and off- of SA (Bateup et al., 2016).

\section{Study limitations}

Some limitations in the present study have been identified during the analysis process. First, the sample size of 21 elite level sailors accounted for 6 fully crewed boats out of 23 . Testing more crew members may have permitted to perform more significant correlational analysis between crew characteristics, as a mean or sum, and ranking. Second, as previously mentioned, sailing relies on bio-informational and strategic qualities to perform. Indeed, overall and specific sailing experience was not accounted for and could have influenced performance and account for discrimination of success.

\section{Conclusion}

466 Overall, the findings have identified multiple variables (technical and physical) that discriminate between successful and less successful athletes/boats. The results can be used as normative data to compare, detect and guide athletes in their preparation for performance. The present study highlights successful sailors having stronger grip strength, more powerful bench-pull and higher IMTP than their less successful counterparts. Successful boats displayed a faster average speed, maximal speed and more efficient starting performance. Nevertheless, these findings should be applied with caution to other populations (i.e. youths, less experimented sailors and other sailing categories). 


\section{Practical applications}

This study may provide useful information to coaches, sports scientists and sailors in the planning and implementation of physical and technical training interventions. Where practitioners wish to evaluate and provide sailors with reliable training interventions the use of handgrip strength, submaximal pulling velocity and isometric mid-thigh pull testing protocols are suitable. We believe that future studies should focus on two particular aspects: (1) identifying the effects of internal and external training load on technical and physical performance indicators during the preparation and competitive phase of the TDF 484 and (2) examining sailors' experience (e.g., vessel, position, training load) in order to 485 identify potential performance and/or talent pathways.

\section{Acknowledgements}

The investigators would like to acknowledge the Sailing Federation (France) and Georacing $®$ for their continued collaboration. 
Side view

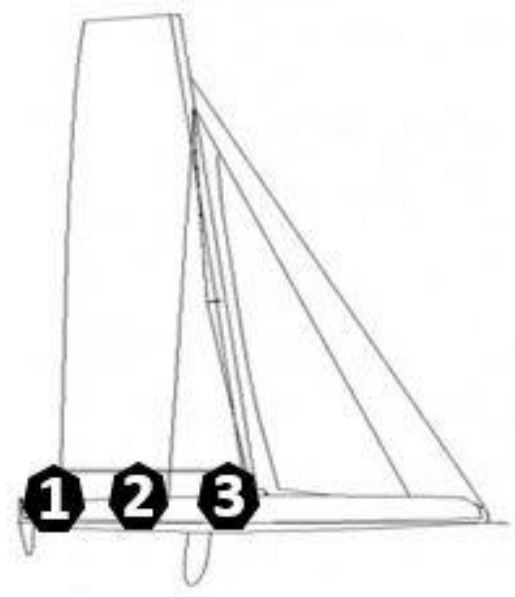

Top view

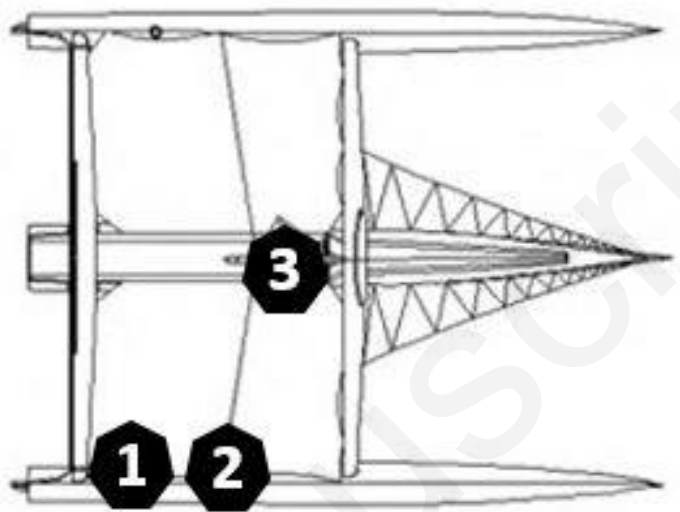

1. Helmsman: reponsible for manoeuvering the boat by acting directly on the rudders.

2. Trimmer: Trims the shape of the sails by acting on the cranks.

3. Bowman: Responsible for the hoisting and the dropping of the sails.

Figure 1. Side and top view of a DIAM24 One Design multihull. The figure shows the position and roles of the 3 athletes on-board. In winds over 10 knots all three sailors are hiking on the same hull. 


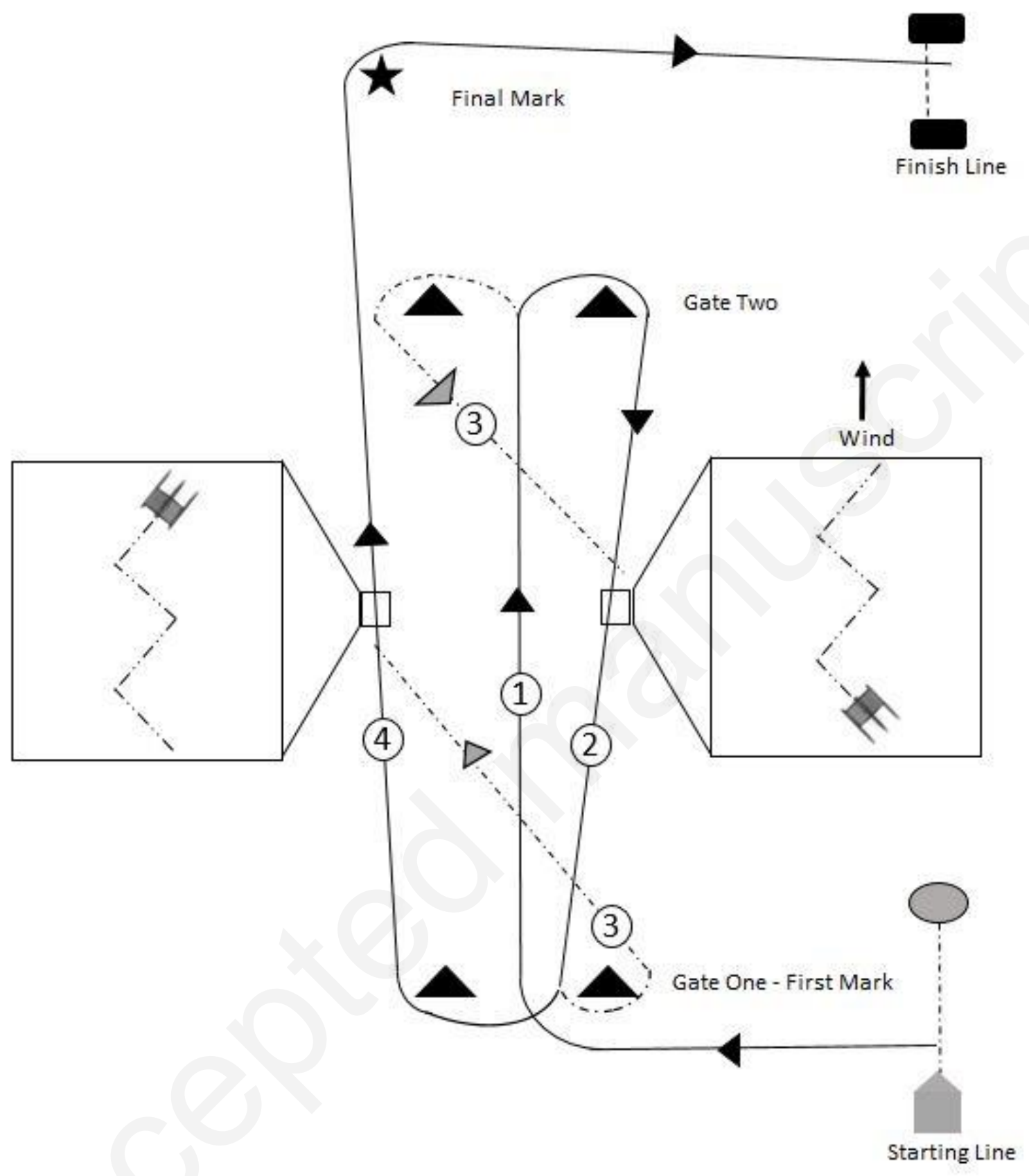

Figure 2. A typical Tour de France nautical stadium course. (1) Represents the downwind portion and (2) the upwind portion. (1) And (2) can be sailed up to three times according to race committee. Teams must go through the gates and can chose to round either mark (3). (4) Represents the final 511 straight before gybing towards the finish line. 


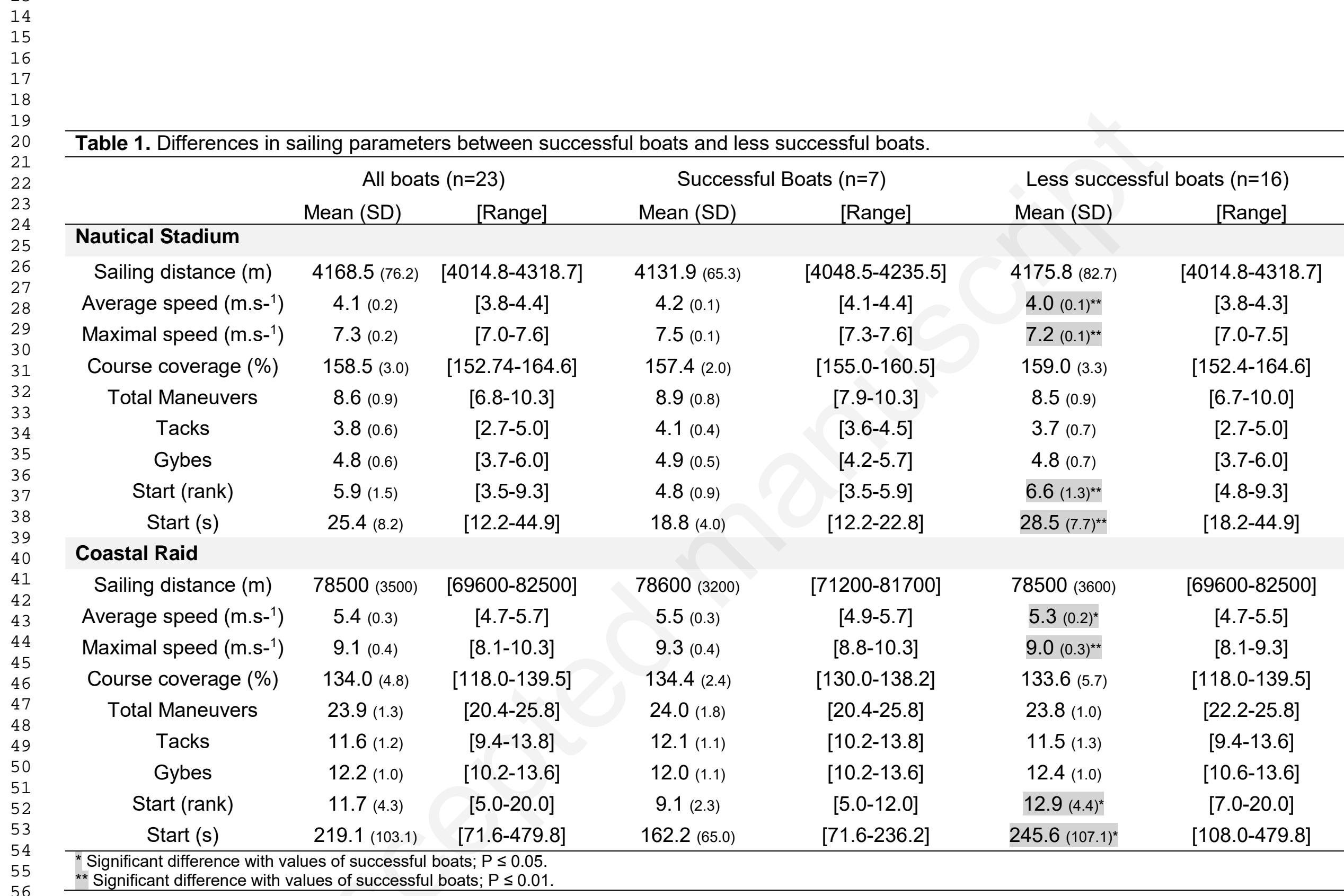


Table 2. Age and anthropometric characteristics (mean (SD)) of TDF sailors.

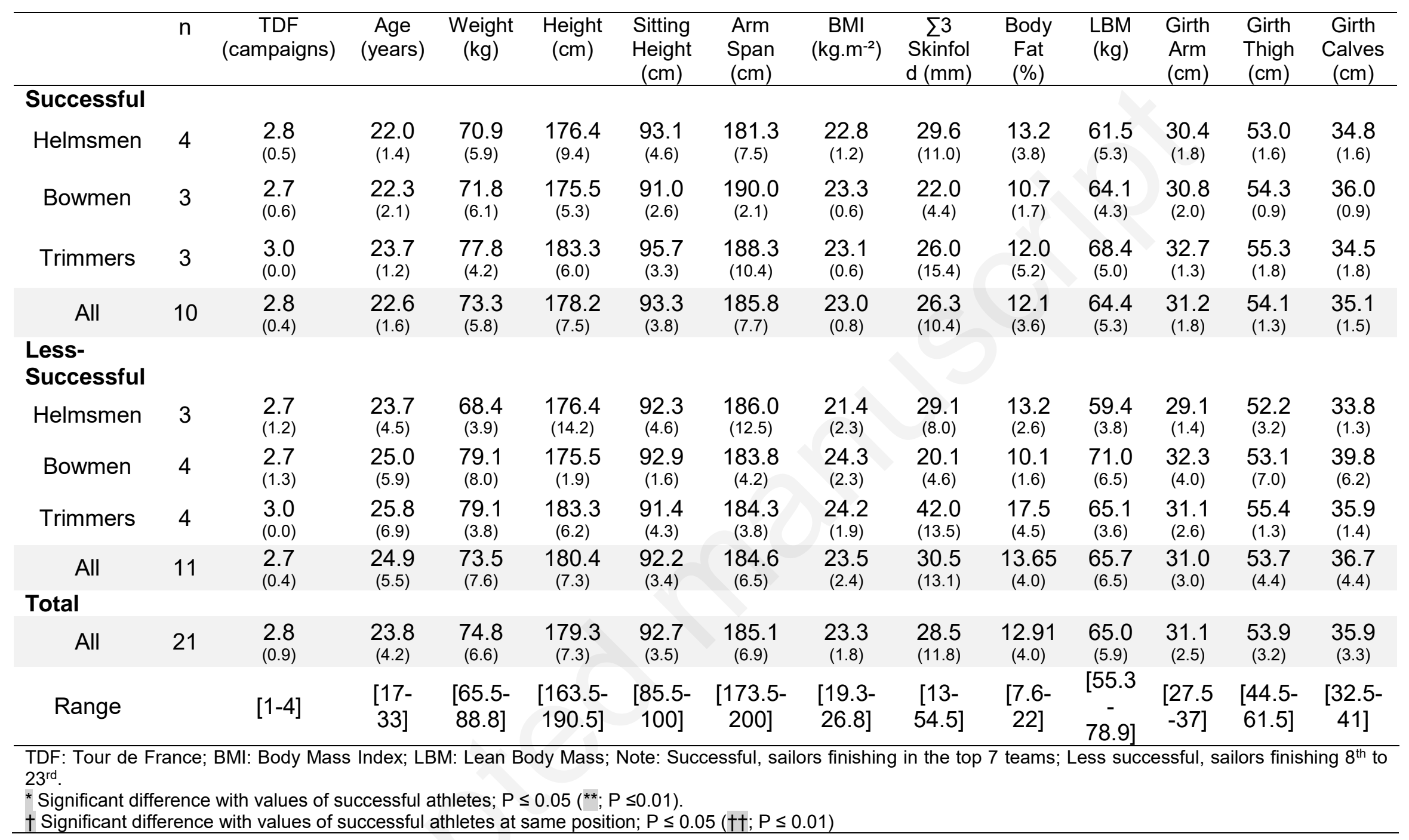

Significant difference with values of successful athletes at same position; $\mathrm{P} \leq 0.05$ ( $†+\mathrm{P} \leq 0.01$ ) 
14 Table 3. Physical and physiological characteristics (mean (SD)) of TDF sailors.

\begin{tabular}{|c|c|c|c|c|c|c|c|c|c|c|c|c|c|c|c|}
\hline $\begin{array}{l}16 \\
17 \\
18\end{array}$ & & $\mathrm{n}$ & $\begin{array}{c}\mathrm{HGS}_{\mathrm{Do}} \\
\mathrm{m}(\mathrm{kg})\end{array}$ & $\begin{array}{c}\mathrm{HGS}_{\mathrm{Su}} \\
\mathrm{m}(\mathrm{kg})\end{array}$ & $\begin{array}{l}\mathrm{SJ}_{\mathrm{H}} \\
(\mathrm{cm})\end{array}$ & $\begin{array}{l}\mathrm{CMJ}_{\mathrm{H}} \\
(\mathrm{cm})\end{array}$ & $\begin{array}{l}\text { IMTP } \\
(\mathrm{N})\end{array}$ & $\begin{array}{c}\text { IMTP }_{\mathrm{W}} \\
\left(\mathrm{N} . \mathrm{kg}^{-}\right. \\
1 \\
)\end{array}$ & $\begin{array}{l}\text { MRWT- } \\
\text { MPO (W) }\end{array}$ & $\begin{array}{l}\mathrm{BP}_{1 \mathrm{R}} \\
\mathrm{M}(\mathrm{kg})\end{array}$ & $\begin{array}{c}\mathrm{BP}_{\mathrm{MPV} 2} \\
0\left(\begin{array}{c}\mathrm{m} . \mathrm{s}^{-} \\
1 \\
)\end{array}\right.\end{array}$ & $\begin{array}{c}\mathrm{BP}_{\mathrm{MPV} 3} \\
0\left(\begin{array}{c}\mathrm{m} . \mathrm{S}^{-} \\
1\end{array}\right)\end{array}$ & $\begin{array}{c}\mathrm{BP}_{\mathrm{MPV} 4} \\
0\left(\begin{array}{c}\mathrm{m} . \mathrm{s}^{-} \\
1 \\
)\end{array}\right.\end{array}$ & $\begin{array}{c}B P_{M P V 5} \\
0\left(\begin{array}{c}m \\
1 \\
1\end{array}\right)\end{array}$ & $\begin{array}{c}\dot{\mathrm{V}} \mathrm{O}_{2 \max } \\
\left(\mathrm{ml} \cdot \mathrm{mn}^{-}\right. \\
\left.{ }^{1} . \mathrm{kg}^{-1}\right)\end{array}$ \\
\hline 19 & Successful & & & & & & & & & & & & & & \\
\hline $\begin{array}{l}21 \\
22\end{array}$ & Helmsmen & 4 & $\begin{array}{l}59.3 \\
(5.6)\end{array}$ & $\begin{array}{c}113.5 \\
(9.7)\end{array}$ & $\begin{array}{l}32.7 \\
(4.8)\end{array}$ & $\begin{array}{l}37.6 \\
(5.2)\end{array}$ & $\begin{array}{c}2649.9 \\
(397.6)\end{array}$ & $\begin{array}{l}37.3 \\
(3.4)\end{array}$ & $\begin{array}{c}501.3 \\
(82.3)\end{array}$ & $\begin{array}{c}73.8 \\
(6.3)\end{array}$ & $\begin{array}{c}1.5 \\
(0.02)\end{array}$ & $\begin{array}{l}1.2 \\
(0.1)\end{array}$ & $\begin{array}{l}1.1 \\
(0.1)\end{array}$ & $\begin{array}{l}0.9 \\
(0.1)\end{array}$ & $\begin{array}{c}53.5 \\
(6.4)\end{array}$ \\
\hline $\begin{array}{l}23 \\
24 \\
25\end{array}$ & Bowmen & 3 & $\begin{array}{l}72.0 \\
(6.9)\end{array}$ & $\begin{array}{c}138.0 \\
(11.1)\end{array}$ & $\begin{array}{c}42.8 \\
(5.5)\end{array}$ & $\begin{array}{l}37.6 \\
(2.2)\end{array}$ & $\begin{array}{c}2894.1 \\
(189.7)\end{array}$ & $\begin{array}{r}40.4 \\
(1.1)\end{array}$ & $\begin{array}{l}623.7 \\
(115.0)\end{array}$ & $\begin{array}{l}83.3 \\
(2.9)\end{array}$ & $\begin{array}{l}1.7 \\
(0.1)\end{array}$ & $\begin{array}{l}1.4 \\
(0.1)\end{array}$ & $\begin{array}{l}1.2 \\
(0.2)\end{array}$ & $\begin{array}{l}1.0 \\
(0.1)\end{array}$ & $\begin{array}{l}52.5 \\
(14.0)\end{array}$ \\
\hline $\begin{array}{l}26 \\
27 \\
28\end{array}$ & Trimmers & 3 & $\begin{array}{l}66.3 \\
(8.5)\end{array}$ & $\begin{array}{c}127.3 \\
(20.1)\end{array}$ & $\begin{array}{c}35.6 \\
(1.0)\end{array}$ & $\begin{array}{l}39.0 \\
(2.4)\end{array}$ & $\begin{array}{c}2955.6 \\
(144.9)\end{array}$ & $\begin{array}{l}38.0 \\
(2.2)\end{array}$ & $\begin{array}{l}632.7 \\
(126.0)\end{array}$ & $\begin{array}{l}81.7 \\
(10.4)\end{array}$ & $\begin{array}{l}1.7 \\
(0.1)\end{array}$ & $\begin{array}{l}1.5 \\
(0.1)\end{array}$ & $\begin{array}{l}1.3 \\
(0.1)\end{array}$ & $\begin{array}{l}1.2 \\
(0.1)\end{array}$ & $\begin{array}{l}56.5 \\
(2.2)\end{array}$ \\
\hline $\begin{array}{l}29 \\
30\end{array}$ & All & 10 & $\begin{array}{r}65.2 \\
(8.3)\end{array}$ & $\begin{array}{c}125.0 \\
(16.3)\end{array}$ & $\begin{array}{l}35.6 \\
(1.0)\end{array}$ & $\begin{array}{l}37.9 \\
(38.6)\end{array}$ & $\begin{array}{c}2814.9 \\
(293.5)\end{array}$ & $\begin{array}{c}38.4 \\
(2.7)\end{array}$ & $\begin{array}{l}577.4 \\
(114.2)\end{array}$ & $\begin{array}{l}79.0 \\
(7.8)\end{array}$ & $\begin{array}{l}1.6 \\
(0.1)\end{array}$ & $\begin{array}{l}1.3 \\
(0.1)\end{array}$ & $\begin{array}{l}1.2 \\
(0.2)\end{array}$ & $\begin{array}{l}1.0 \\
(0.1)\end{array}$ & $\begin{array}{r}54.1 \\
(7.8)\end{array}$ \\
\hline $\begin{array}{l}31 \\
32\end{array}$ & $\begin{array}{l}\text { Less- } \\
\text { Successful }\end{array}$ & & & & & & & & & & & & & & \\
\hline $\begin{array}{l}33 \\
34 \\
35\end{array}$ & Helmsmen & 3 & $\begin{array}{l}56.3 \\
(15.4)\end{array}$ & $\begin{array}{c}110.3 \\
(27.5)\end{array}$ & $\begin{array}{c}39.3 \\
(7.7)\end{array}$ & $\begin{array}{c}36.5 \\
(4.7)\end{array}$ & $\begin{array}{c}2433.4 \\
(776.7)\end{array}$ & $\begin{array}{c}35.2 \\
(9.8)\end{array}$ & $\begin{array}{c}488.7 \\
(46.0)\end{array}$ & $\begin{array}{c}67.5 \\
(4.3)\end{array}$ & $\begin{array}{l}1.3 \\
(0.2)\end{array}$ & $\begin{array}{l}1.1 \\
(0.0)\end{array}$ & $\begin{array}{c}1.0 \\
(0.06)\end{array}$ & $\begin{array}{c}0.8 \\
(0.06)\end{array}$ & $\begin{array}{l}48.7 \\
(13.6)\end{array}$ \\
\hline $\begin{array}{l}36 \\
37\end{array}$ & Bowmen & 4 & $\begin{array}{l}58.3 \\
(9.9)\end{array}$ & $\begin{array}{c}114.3 \\
(18.9)\end{array}$ & $\begin{array}{l}36.8 \\
(5.8)\end{array}$ & $\begin{array}{r}38.7 \\
(7.5)\end{array}$ & $\begin{array}{c}2723.2 \\
(614.7)\end{array}$ & $\begin{array}{l}34.3 \\
(5.7)\end{array}$ & $\begin{array}{l}586.0 \\
(109.4)\end{array}$ & $\begin{array}{l}88.8 \\
(20.15)\end{array}$ & $\begin{array}{c}1.5 \\
(0.1) \dagger\end{array}$ & $\begin{array}{l}1.4 \\
(0.2)\end{array}$ & $\begin{array}{l}1.2 \\
(0.2)\end{array}$ & $\begin{array}{l}1.0 \\
(0.2)\end{array}$ & $\begin{array}{l}57.3 \\
(13.6)\end{array}$ \\
\hline $\begin{array}{l}38 \\
39 \\
10\end{array}$ & Trimmers & 4 & $\begin{array}{l}57.3 \\
(5.9)\end{array}$ & $\begin{array}{c}110.8 \\
(11.8)\end{array}$ & $\begin{array}{l}31.0 \\
(5.6)\end{array}$ & $\begin{array}{l}35.8 \\
(6.8)\end{array}$ & $\begin{array}{c}2527.7 \\
(377.5)\end{array}$ & $\begin{array}{l}31.9 \\
(3.4) \dagger\end{array}$ & $\begin{array}{c}575.0 \\
(66.4)\end{array}$ & $\begin{array}{l}70.0 \\
(13.5)\end{array}$ & $\begin{array}{c}1.3 \\
(0.1)+t\end{array}$ & $\begin{array}{c}1.2 \\
(0.1)+\dagger\end{array}$ & $\begin{array}{c}1.1 \\
(0.1) \dagger\end{array}$ & $\begin{array}{l}0.9 \\
(0.3)\end{array}$ & $\begin{array}{l}51.4 \\
(6.8)\end{array}$ \\
\hline $\begin{array}{l}4 \odot \\
41 \\
42\end{array}$ & All & 11 & $\begin{array}{l}57.4 \\
(9.4)^{*}\end{array}$ & $\begin{array}{c}111.9 \\
(17.5)\end{array}$ & $\begin{array}{c}35.4 \\
(6.7)\end{array}$ & $\begin{array}{c}37.1 \\
(6.1)\end{array}$ & $\begin{array}{c}2573.1 \\
(540.8)\end{array}$ & $\begin{array}{l}33.7 \\
(5.9)^{*}\end{array}$ & $\begin{array}{c}555.5 \\
(84.9)\end{array}$ & $\begin{array}{l}76.1 \\
(16.8)\end{array}$ & $\begin{array}{l}1.3 \\
(0.2)^{* *}\end{array}$ & $\begin{array}{l}1.2 \\
(0.2)\end{array}$ & $\begin{array}{l}1.1 \\
(0.1)\end{array}$ & $\begin{array}{l}0.9 \\
(0.2)\end{array}$ & $\begin{array}{c}52.8 \\
(9.4)\end{array}$ \\
\hline $\begin{array}{l}42 \\
43\end{array}$ & Total & & & & & & & & & & & & & & \\
\hline $\begin{array}{l}43 \\
44 \\
45\end{array}$ & All & & $\begin{array}{l}61.1 \\
(9.5)\end{array}$ & $\begin{array}{c}118.1 \\
(17.8)\end{array}$ & $\begin{array}{l}36.0 \\
(6.2)\end{array}$ & $\begin{array}{c}38.6 \\
(5.6)\end{array}$ & $\begin{array}{c}2688.2 \\
(447.5)\end{array}$ & $\begin{array}{c}35.9 \\
(5.1)\end{array}$ & $\begin{array}{c}565.9 \\
(97.9)\end{array}$ & $\begin{array}{l}77.5 \\
(13.0)\end{array}$ & $\begin{array}{l}1.5 \\
(0.2)\end{array}$ & $\begin{array}{l}1.3 \\
(0.2)\end{array}$ & $\begin{array}{l}1.1 \\
(0.2)\end{array}$ & $\begin{array}{l}1.0 \\
(0.2)\end{array}$ & $\begin{array}{c}53.4 \\
(8.5)\end{array}$ \\
\hline $\begin{array}{l}46 \\
47 \\
48\end{array}$ & Range & & [46-80] & $\begin{array}{l}{[90-} \\
150]\end{array}$ & $\begin{array}{l}{[24.1-} \\
49.1]\end{array}$ & $\begin{array}{c}{[26.2-} \\
46.7]\end{array}$ & $\begin{array}{c}{[1567 .} \\
5- \\
3160]\end{array}$ & $\begin{array}{c}{[24.5-} \\
43.7]\end{array}$ & [430-774] & $\begin{array}{l}{[50-} \\
105]\end{array}$ & $\begin{array}{r}{[1.04-} \\
1.83]\end{array}$ & $\begin{array}{c}{[1.06-} \\
1.63]\end{array}$ & $\begin{array}{c}{[0.92-} \\
1.45]\end{array}$ & $\begin{array}{c}{[0.77-} \\
1.29]\end{array}$ & $\begin{array}{l}{[36.5-} \\
76.8]\end{array}$ \\
\hline
\end{tabular}

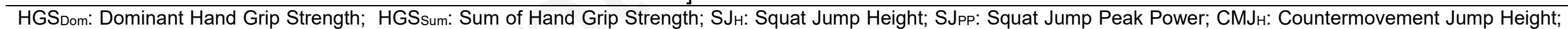

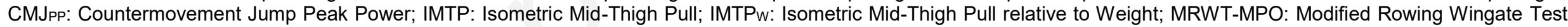

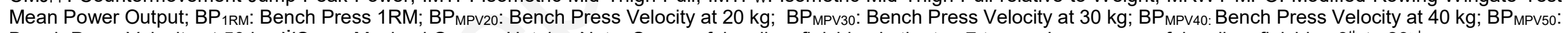
Bench Press Velocity at $50 \mathrm{~kg}$; $\mathrm{VO}_{2 \max }$ : Maximal Oxygen Uptake. Note: Successful, sailors finishing in the top 7 teams; Less successful, sailors finishing $8^{\text {th }}$ to $23^{\text {rd }}$.

* Significant difference with values of successful athletes; $P \leq 0.05$ (**; $P \leq 0.01$ ).

$\dagger$ Significant difference with values of successful athletes at same position; $P \leq 0.05(\dagger \dagger ; P \leq 0.01)$

$5 \longdiv { 5 1 4 }$

56

57

58

59

60

61

62

63 


\section{References}

Aagaard, P., Beyer, N., Simonsen, E. B., Larsson, B., Magnusson, S. P. \& Kjaer, M. (1998). Isokinetic muscle strength and hiking performance in elite sailors. Scandinavian Journal of Medicine \& Science in Sports, 8, 138-144.

Amann, M., Subudhi, A., and Foster, C., (2004). Influence of Testing Protocol on Ventilatory Thresholds and Cycling Performance. Medecine and Science in Sports and Exercise, 36, No. 4, 613-622.

Anastasiou, A., Jones, T., Mullan, P., Ross, E., \& Howatson, G. (2019). Descriptive analysis of Olympic class windsurfing competition during the 2017-2018 regatta season. International Journal of Performance Analysis in Sport, 19(4), 517-529.

Araújo, D., \& Sepra, S. (1997). Towards a construction of methodological design to measuring decision making in externally paced sport : the case of sailing. In In Innovations in sport psychology: linking theory and practice : proceedings, pt. l., The Zinmann College of Physical Education and Sport Sciences, The Wingate Institute for Physical Education and Sport, p.76-78.

Araújo, D., Davids, K., Diniz, A., Rocha, L., Santos, J. C., Dias, G., \& Fernandes, O. (2015). Ecological dynamics of continuous and categorical decision-making: The regatta start in sailing. European Journal of Sport Science, 15(3), 195-202.

Balsalobre-Fernandez, C., Glaister, M., \& Lockey, R. A. (2015). The validity and reliability of an iPhone app for measuring vertical jump performance. Journal of Sports Sciences, $1-6$.

Bateup, B., Thornton, H., Withers, S. \& Duthie, G. (2016) The Influence of Training Load on Markers of Fatigue in Junior Male Semi-Elite Sailors. Journal of Australian Strength \& Conditioning, 24(6), 21-22.

Batterham, AM. and Hopkins, WG. (2006). Making meaningful inferences about magnitudes. International Journal of Sports Physiology and Performance, 1, 50-57.

Bay, J., \& Larsson, B. (2013). Bay testen. En fysiologisk performance test for 49'er gaster [A physiological performance test for 49'er crewmen] (Unpublished thesis). Copenhagen: Team Danmark and Department of Nutrition, Exercise and Sports Sciences, University of Copenhagen/Team Danmark.

Bernardi, M., Quattrini, F., Rodio, A., Fontana, G., Madaffari, A., Brugnoli, M. \& Marchetti, M. (2007). Physiological characteristics of America's Cup sailors. Journal of Sports Sciences, 25, no. 10, 1141-1152.

Blackburn, MJ., \& Hubinger, I. (1995). Determination of physiological profiles and exercise training programs for competitive dinghy sailors. National Sports Research Centre, 1-16. 
Bojsen-Møller, J., Larsson, B., Magnusson, S. P., \& Aagaard, P. (2007). Yacht type and crew-specific differences in anthropometric, aerobic capacity, and muscle strength parameters among international Olympic class sailors. Journal of Sports Sciences, 25(10), 1117-1128.

Bourgois, J. G., Callewaert, M., Celie, B., De Clercq, D., \& Boone, J. (2016). Isometric quadriceps strength determines sailing performance and neuromuscular fatigue during an upwind sailing emulation. Journal of Sports Sciences, 34(10), 973-979.

Brozek J, Grande F, Anderson JT, Keys A. Densitometric analysis of body composition: revision of some quantitative assumptions. Ann. N. Y. Acad. Sci. 1963;110:113-140.

Caimmi, G., \& Semprini, G. (2017). Heart rate and GPS data analysis of kiteboard course racing during the Italian Championship. Sport Sciences for Health, 13(1), 79-85.

Castagna, O., \& Brisswalter, J. (2007). Assessment of energy demand in Laser sailing: influences of exercise duration and performance level. European Journal of Applied Physiology, 99(2), 95-101.

Chicoy, I. \& Encarnación-Martínez, A. (2015). Determining Factors in the Performance of Hiking in Dinghy Sailing: A Literature Review. Motricidad: European Journal of Human Movement, 34, 15-33.

Cronin, J., Lawton, T., Harris, N., Kilding, A. \& Mcmaster, DT. (2017). A Brief Review of Handgrip Strength and Sport Performance. Journal of Strength \& Conditioning Research, 31(11), 3187-3217.

Cummins, C., Orr, R., O'Connor, H., \& West, C. (2013). Global Positioning Systems (GPS) and Microtechnology Sensors in Team Sports: A Systematic Review. Sports Medicine, 43(10), 1025-1042.

Dieli-Conwright, C., Jensky, N. \& Battaglia, G. and McCauley, S. and Todd Schroeder, E. (2009). Validation of the CardioCoachCO2 for Submaximal and Maximal Metabolic Exercise Testing. Journal of strength and conditioning research, 23, 1316-20.

Duthie, G. M. (2006). A Framework for the Physical Development of Elite Rugby Union Players. International Journal of Sports Physiology \& Performance, 1(1), 2-13.

Fernandez-Fernandez, J., Sanz-Rivas, D. and Mendez-Villanueva, A. (2009). A Review of the Activity Profile and Physiological Demands of Tennis Match Play. Strength and Conditioning Journal, 31(4), 15-26.

Haff, G., Nimphius, S. and Sheppard, JM. (2013). The reliability of isometric force-time variables collected on a portable mid-thigh pull testing device. Journal of Strength Conditioning Research, 27(10), 98-99.

Hurdiel, R., Van Dongen, H., Aron, C., McCauley, P., Jacolot, L. and Theunynck, D. (2014). Sleep restriction and degraded reaction-time performance in Figaro solo sailing races. Journal of Sports Sciences, 32(2), 172-174. 
Jackson, AS. and Pollock, ML. (1978). Generalized equations for predicting body density of men 1978. British Journal of Nutrition, 40, 497-504.

Larsson, B., Beyer, N., Bay, P., Blond, L., Aagaard, P. and Kjaer, M. (1996). Exercise performance in elite male and female sailors. International Journal of Sports Medicine, 17(7), 504-508.

Léger, D., Elbaz, M., Raffray, T., Metlaine, A., Bayon, V., \& Duforez, F. (2008). Sleep management and the performance of eight sailors in the Tour de France à la voile yacht race. Journal of Sports Sciences, 26(1), 21-28.

Manzanares Serrano, A., Segado Segado, F., \& Menayo Antúnez, R. (2012). Factores determinantes del rendimiento en vela deportiva: revisión de la literatura. / Decisive factors in Sailing Performance: Literature review. Cultura, Ciencia y Deporte, 7(20), 125134.

Marfell-Jones, M., Olds, T., Stewart, A., \& Carter, J. E. L. (2006). International standards for anthropometric assessment. Potchefst-room, South Africa: ISAK.

Neville, V., Calefato, J., Pérez-Encinas, C., Rodilla-Sala, E., Rada-Ruiz, S., Dorochenko, P., \& Folland, J. (2009). America's Cup yacht racing: Race analysis and physical characteristics of the athletes. Journal of Sports Sciences, 27(9), 915-923.

Pearson, S. N., Hume, P. A., Cronin, J. B., \& Slyfield, D. (2009). Strength and Power Determinants of Grinding Performance in America's Cup Sailors. Journal of Strength \& Conditioning Research, 23(6), 1883-1889.

Pérez-Turpin, J. A., Cortell-Tormo, J. M., C. Suárez-Llorca, Andreu-Cabrera, E., LlanaBelloch, S., \& Pérez-Soriano, P. (2009). Relationship between Anthropometric Parameters, Physiological Responses, Routes and Competition Results in Formula Windsurfing. Acta Kinesiologiae Universitatis Tartuensis, 14, 95-110.

611 Peterson Silveira, R., Stergiou, P., Carpes, FP., Castro, FA., Katz, L and Stefanyshyn, DJ. (2017). Validity of a portable force platform for assessing biomechanical parameters in three different tasks. Sports Biomechanics, 16(2), 177-186.

Pluijms, J. P., Cañal-Bruland, R., Hoozemans, M. J. M., \& Savelsbergh, G. J. P. (2015). Visual search, movement behaviour and boat control during the windward mark rounding in sailing. Journal of Sports Sciences, 33(4), 398-410.

Portier, H., \& Guezennec, C. Y. (2003). Estimation de la depense energetique lors d'une regate en deriveur. / Oxygen cost assessment during small craft competition. Science \& Sports, 18(2), 111-113.

Pulur, A. (2011). Determination of physical and physiological profiles of international elite sailors. African Journal of Business Management, 5 (8), 3071-3075.

Ran Wang, Hoffman, JR., Tanigawa, S., Miramonti, AA., La Monica, MB., Beyer, KS., Church, D., Fukuda, D. and Stout, JR. (2016). Isometric mid-thigh pull correlates with 
strength, sprint, and agility performance in collegiate rugby union players. Journal of Strength and Conditioning Research, 30(11), 3051-3056.

Riechman, S. E., Zoeller, R. F., Balasekaran, G., Goss, F. L., \& Robertson, R. J. (2002). Prediction of $2000 \mathrm{~m}$ indoor rowing performance using a $30 \mathrm{~s}$ sprint and maximal oxygen uptake. Journal of Sports Sciences, 20(9), 681-687.

Roczniok, R., Maszczyk, A., Stanula, A., Czuba, M., Pietraszewski, P., Kantyka, J., \& Starzyński, M. (2013). Physiological and physical profiles and on-ice performance approach to predict talent in male youth ice hockey players during draft to hockey team. Isokinetics \& Exercise Science, 21(2), 121-127.

Sánchez-Medina, L., González-Badillo, J. J., Pérez, C. E., \& Pallarés, J. G. (2014). Velocity- and Power-Load Relationships of the Bench Pull vs. Bench Press Exercises. International Journal of Sports Medicine, 35(3), 209-216.

Shaharudin, S. and Zanotto, D. and Agrawal, S. (2014). Muscle Synergy during Wingate Anaerobic Rowing Test of Collegiate Rowers and Untrained Subjects. International Journal of Sports Science, 4, 165-172.

Spiro SG. (1977). Exercise testing in clinical medicine. Br J Dis Chest. Jul;71(3):145-72

Svantesson, U., Nordé, M., Svensson, S., \& Brodin, E. (2009). A comparative study of the Jamar $\circledast$ and the Grippit $\circledast$ for measuring handgrip strength in clinical practice. Isokinetics \& Exercise Science, 17(2), 85-91.

Tan, B., Aziz, A. R., Spurway, N. C., Toh, C., Mackie, H., Wei Xie, James Wong, Fuss, F. K., Kong Chuan Teh, Xie, W., Wong, J., \& Teh, K. C. (2006). Indicators of maximal hiking performance in Laser sailors. European Journal of Applied Physiology, 98(2), 169-176.

Thill, E. (1982). La detection sportive a partir de criteres psychologiques. In Dans, Rioux, G. et Thill, E. (eds.), Competition sportive et psychologie: Journees europeennes de psychologie du sport, Paris, Chiron, c1982, p. 77-94.

Vangelakoudi, A., Vogiatzis, I., \& Geladas, N. (2007). Anaerobic capacity, isometric endurance, and Laser sailing performance. Journal of Sports Sciences, 25(10), 10951100 .

Vehrs, P. R., Keller, D. M., George, J. D., Hager, R. L., \& Fellingham, G. W. (2007). Monitoring O2max during Fourteen Weeks of Endurance Training Using the Cardiocoach. Journal of Strength \& Conditioning Research, 21(1), 62-66.

Ward, P., Williams, A. M., \& Bennett, S. J. (2002). Visual search and biological motion perception in tennis. Research Quarterly for Exercise \& Sport, 73(1), 107-112. 